\title{
The efficiency of hemodialysis in transfusion-related acute lung injury (TRALI): A case report
}

\author{
Ugur Goktas, Nureddin Yuzkat ${ }^{\star}$, Lokman Soyoral, M. Bilal Cegin, Abdullah Kahraman
}

Department of Anesthesiology, Faculty of Medicine, Yuzuncu Yil University, Van, Turkey

\begin{abstract}
Transfusion-Related Acute Lung Injury (TRALI) is an important life-threatening complication that is related with blood transfusion. The frequency is reported as $1 / 5.000$. It is generally characterized with hypoxia that appears at the $2-6^{\text {th }}$ hours after the blood transfusion, bilateral infiltration in the chest radiography, and non-cardiogenic pulmonary edema. Acute respiratory distress, hypotension, tachycardia and fever accompany the clinical picture. Past surgery, blood transfusion, and sepsis are among the factors that trigger the disease. In this study, the efficiency of the hemodialysis applied in the right time in the treatment of a heavy TRALI case developed after a blood transfusion has been presented.
\end{abstract}

Key Words: Acute lung injury, efficiency, hemodialysis, transfusion

\section{Introduction}

Transfusion-Related Acute Lung Injury (TRALI) is an important life-threatening complication that is related with blood transfusion. The frequency is reported as $1 / 5.000$. Nearly $70 \%$ of the cases need mechanical ventilation, and the mortality of TRALI is around $8-9 \%$ (1). It is generally characterized with hypoxia that appears at the 2$6^{\text {th }}$ hours after the blood transfusion, bilateral infiltration in the chest radiography, and noncardiogenic pulmonary edema (2). Acute respiratory distress, hypotension, tachycardia and fever accompany the clinical picture (3). Past surgery, blood transfusion, and sepsis are among the factors that trigger the disease (4).

TRALI is defined as the endothelial damage of the lungs and its pathogenesis has not been explained fully yet. However, it is considered that the granulocyte antibodies in the donor plasma, active neutrophil human leukocytes antigen-1 (HLA)-1, HLA-2 antibodies are intermediaries in the pathogenesis $(5,6)$. It has also been reported that biologically active lipids like lisophosphateidilcholine have also roles in the development of TRALI (7).

In this study, the efficiency of the hemodialysis applied in the right time in the treatment of a heavy TRALI case developed after a blood transfusion has been presented.

\section{Case report}

It has been learnt that a 19-year-old male patient received splenectomy, left nephrectomy and colon resection in a medical center after a wounding by firearm. 4U whole blood, 6U RBS (Red blood Suspension), 6U FFP (Fresh Frozen Plasma) were transfused to the patient intraoperatively.

The patient was admitted to the Intensive Care Unit in our center. The Postoperative GCS (Glasgow Coma Score) was 5 points, therefore the patient was sedated with midazolam for 12 hours. After the sedation was terminated, the GCS was $10+$ intubated. During the postoperative 4 days, the patient was intubated and followed with endotracheal tube (ETT). He was extubated on the 5 th day. During the first 5 days, the patient was given $7 \mathrm{U}$ ES, $15 \mathrm{U}$ TDP, and around 16 hours after the extubation, sudden respiratory distress, hypoxemia (PO2: $51 \mathrm{mmHg}, \mathrm{SpO} 2: 78 \%$ ), and hypotension $(81 / 50 \mathrm{mmHg})$ were observed in the patient, and therefore he was reintubated with ETT (Table 1). Pulmonary edema in the lungs was detected in the case; and also, bilateral infiltration was observed in the chest radiography (Figure 1). There were no problems in the EKO, and the CVP (Central Venous Pressure) values were within the normal limits. There were no findings for infection in the laboratory findings.

This study was presented as a poster presentation in 17th National Congress of the Intensive Care Congress, 23-27 April 2014, Antalya, Turkey

${ }^{*}$ Corresponding Author: Nureddin Yuzkat, MD., Yuzuncu Yil University, Faculty of Medicine, Department of Anesthesiology, Van, Turkey Phone: +90 505229 4728, E-mail: nyuzkat@gmail.com

Received: 05.04.2015, Accepted: 06.04.2015 
The case was accepted as TRALI. No more blood products were given. Anuria developed in the case, and the kidney functions started to become disrupted (creatinine: 4.6). Hemodialysis for 3 hours for 2 subsequent days was applied to the patient. Lung protective ventilation (tidal volume: 4-6mL/kg, PEEP: 8-12 $\mathrm{cmH}_{2} \mathrm{O}$, number of respiration: $12-18$ breath/min, $\mathrm{FiO}_{2}: 50-80 \%$, PS: $8-12 \mathrm{cmH}_{2} \mathrm{O}$ ) was applied to the patient for 3 days. He was sedated for 2 days with midazolam. The kidney functions of the case became normal, and the respiratory parameters also became normal with the second seance dialysis (Figure 2) (Table 2). Reintubation was extubated on the $4^{\text {th }}$ day (creatinine: 1.7), and he was sent to the service without any problems on the $14^{\text {th }}$ day of his hospitalization in the ICU (creatinine: 1.1).

\section{Discussion}

TRALI was first defined clinically in 2004. It is a non-cardiogenic pulmonary edema observed as secondary to the transfusion and hypoxemia.

Table 1. The decision of transfusion patients in the intensive care unit

\begin{tabular}{|c|c|c|c|c|c|}
\hline & & & & ransfusion & \\
\hline & & $\begin{array}{l}\text { Whole } \\
\text { blood }\end{array}$ & $\begin{array}{l}\text { Red blood } \\
\text { suspension }\end{array}$ & $\begin{array}{c}\text { Fresh frozen } \\
\text { plasma }\end{array}$ & Transfusion Decision \\
\hline Intraoperative & GC poorly, & 4 unit & 6 unit & 6 unit & $\begin{array}{l}\text { Acute bleeding, low } \\
\text { hematocrit }\end{array}$ \\
\hline Perioperative & GC poorly, & d, intubated & 4 unit & 2 unit & Hb: 7.5, INR: 1.7 \\
\hline $1^{\text {th }}$ day & GC good, cc & , intubated & 1 unit & 2 unit & Hb: 9.7, INR: 1.7 \\
\hline $2^{\text {th }}$ day & Reoperation & & & 2 unit & INR: 2.05 \\
\hline $3^{\text {th }}$ day & GC good, in & & & 4 unit & INR: 1.89 \\
\hline $4^{\text {th }}$ day & GC good, es & & 2 unit & 2 unit & Hb: 8, INR: 1.7 \\
\hline $5^{\text {th }}$ day & GC poorly, & ated & & 3 unit & INR: 1.7 \\
\hline $6^{\text {th }}$ day & $\begin{array}{r}\text { GC poorly, } \\
\text { hemodialysis }\end{array}$ & , intubatec & ALI, Re & ure, & \\
\hline $7^{\text {th }}$ day & $\begin{array}{r}\text { GC poorly } \\
\text { hemodialysis }\end{array}$ & intubated, & ALI, Renal & ire, & \\
\hline $8^{\text {th }}$ day & Extubated, & ing oxygen & & & \\
\hline $14^{\text {th }}$ day & GC good, d & & & & Hb: 10.2, INR:1.4 \\
\hline
\end{tabular}

GC: General Condition TRALI: Transfusion-Related Acute Lung Injury Hb: Hemoglobin INR: International normalized ratio

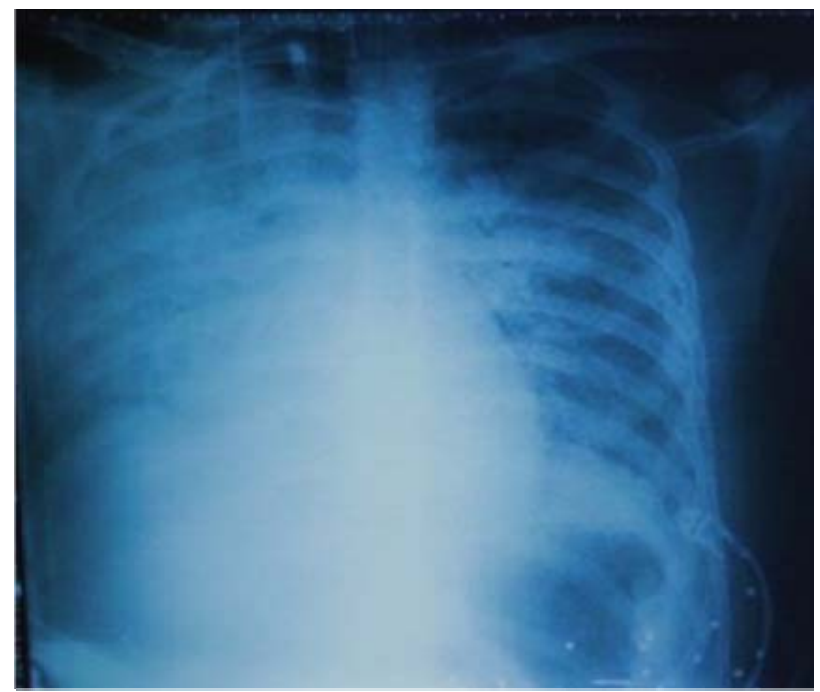

Fig. 1. Pulmonary edema and bilateral infiltration in the case lung.

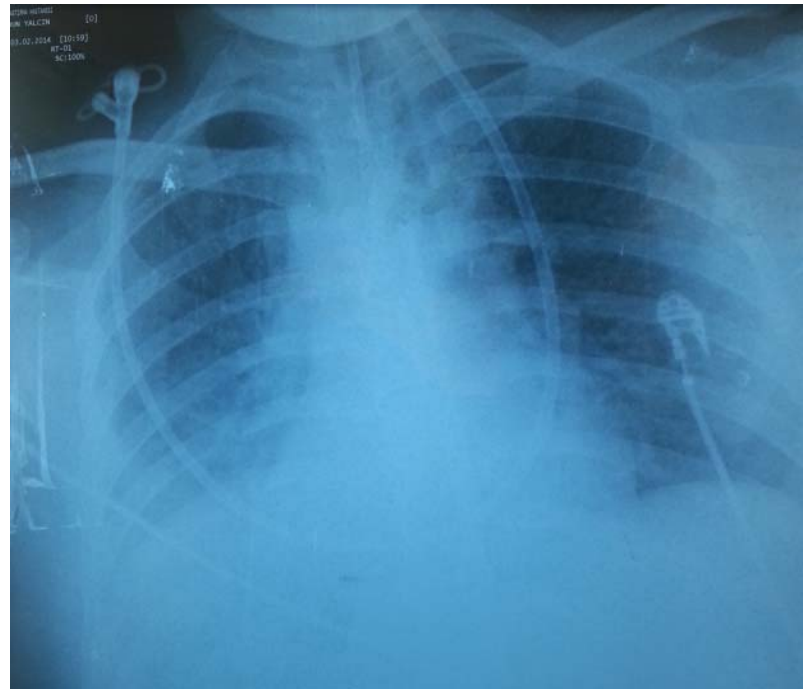

Fig. 2. Chest X-ray of the patient after extubation. 
Table 2. The blood gas samples of the case

\begin{tabular}{|c|c|c|c|c|c|}
\hline & Before TRALI & TRALI $1^{\text {th }}$ day & TRALI $2^{\text {th }}$ day & Extubation & Discharge \\
\hline $\mathrm{pH}$ & 7.36 & 7.31 & 7.45 & 7.45 & 7.37 \\
\hline $\mathrm{PCO}_{2}$ & 36 & 37 & 33 & 28 & 38 \\
\hline $\mathrm{pO}_{2}$ & 48 & 46 & 47 & 55 & 78 \\
\hline $\mathrm{HCO}_{3}$ & 21 & 19 & 22 & 19 & 20 \\
\hline BEECF & -3 & -6 & -1 & -3 & 1 \\
\hline $\mathrm{SaO}_{2}$ & 93 & 89 & 86 & 90 & 91 \\
\hline $\mathrm{FiO}_{2}$ & Nasal 2-4 L/min & $80 \%$ & $60 \%$ & Nasal 2-4 L/min & Oxygen Free \\
\hline
\end{tabular}

TRALI is the major cause for mortality and morbidity related with transfusion, and may occur due to any blood product transfusion (8). It is especially observed due to the transfusion of Fresh Frozen Plasma. The diagnosis is made via the acute lung injury development during or after the transfusion or within the first 6 hours of the transfusion; and the existence of ALI clinical picture before the transfusion, and with elimination of the other risk factors that may lead to this disease (9).

Holness et al (10) conducted a study in which they examined the deaths occurring due to TRALI, and reported that mortality was observed in 58 cases after the transfusion within a 5 -year period. They also reported that erythrocyte transfusion was applied to the one-third of the cases who developed TRALI, and Fresh Frozen Plasma transfusions were applied to half of the cases.

Pulmonary edema, capillary leukocytosis and neutrophil extravasation are observed in TRALI histologically. There are leukocyte antibodies in the thrombocyte concentration and in the TDP obtained from multiparous donors.

The free neutrophil existing in the cell contents in the blood of the banks make us consider that they may lead to TRALI (11). The frequency is 0.04$0.16 \%$ per patient receiving transfusion $(5,7)$. The most frequent clinical characteristics related with the TRALI reported in the literature are difficulty in breathing, bubbly phlegm, pulmonary infiltrations and hypoxia (10). Circulatory load that may lead to respiratory insufficiency after the transfusion, anaphylactic reactions, bacterial contamination and hemolytic transfusion reactions and similar reasons must be considered in the differential diagnosis (8).

There is no specific treatment for TRALI (8). However, when TRALI is suspected, firstly the transfusion must be terminated in the treatment. Oxygenation support and -if necessary- mechanical ventilation must be applied. It is important that the hypovolemia is corrected. For this reason, diuretics must be avoided. The advantages and disadvantages of the steroids are not clear. TRALI is a complication that may be fatal, and rarely progresses with light symptoms (9).

As a consequence, the complications like TRALI whose mortalities are high must be diagnosed early, and the blood transfusion must be limited. Also, the necessary supportive treatment must be applied. We consider that hemodialysis will remove both the inflammatory mediators that affect the lungs and the renal solute load, and contribute to the clinical picture in a fast pace.

\section{References}

1. Bux J, Ulrich JH. Sachs. The pathogenesis of transfusion-related acute lung injury (TRALI). British Journal of Haematology 2007; 136: 788-799.

2. Chu LF, Fuller AJ. Çeviri: Turkan M. Kan ürünleri tedavisi. In: Klinik anesteziyoloji el kitabi. Çeviri Ed: Özcengiz D, Birbiçer H, Inanoglu K, Oksuz H, Ganidagli S. Ankara: Akademisyen 2014: 209-214.

3. Bolaman Z, Camci C, Sönmez HM, et al. High Dose Methylprednisolone Treatment of Transfusion Related Acute Lung Injury: Case Report. ADÜ Tip Fak. Dergisi 2000; 1: 43-46.

4. Bas T, Malbora B, Capanoglu M, Isik O, Kutsal A. Recurrent transfusion-related acute lung injury after open heart surgery: a case report. Türk Gögüs Kalp Damar Cerrahisi Dergisi 2013; 21: 483-486.

5. Kopko PM, Popovsky MA, MacKenzie MR, et al. HLA class II antibodies in transfusionrelated acute lung injury. Transfusion 2001; 41: 1244-1248.

6. McKenzie CG, Kim M, Singh TK, et al. Peripheral blood monocyte-derived chemokine blockade prevents murine transfusion-related acute lung injury (TRALI). Blood 2014; 123: 3496-3503.

7. Silliman CC, Boshkov LK, Mehdizadehkashi Z, et al. Transfusion-related acute lung injury: 
epidemiology and a prospective analysis of etiologic factors. Blood 2003; 101: 454-462.

8. Gunay C, Cingoz F, Sahin MA, et al. Transfusion related acute lung injury after open heart surgery. Gulhane Med J 2008; 50: 131-133.

9. Besisik SK, Karahan G, Oztürk G, et al. Transfusion related acute lung injury. Nobel Med 2011; 7: 110-113.
10. Holness L, Knippen MA, Simmons L, Lachenbruch PA. Fatalities caused by TRALI. Transfusion Medicine Reviews 2004; 18: 184-188.

11. Popovsky MA, Moore SB. Diagnostic and pathogenetic considerations in transfusion-related acute lung injury. Transfusion 1985; 25: 573-577.

East J Med Volume:21, Number:4, October-December/2016 